\title{
The effect of drawing ratio in deep drawing process on thickness distribution along the cup
}

\author{
Dr.A.D.Younis \\ University of Mosul
}

\begin{abstract}
In the present study the effect of drawing ratio in deep drawing process on the thickness distribution along the cup (wall, base and nose) has been performed. Obviously, the drawing ratio is the one of the most important parameter has been adopted to design the drawing die. Both experimental and numerical models were carried out on various drawing ratios $(1.484,1.589,1.739,1.908,2.12$ and 2.332).T the simulation results showed that the best drawing ratio is $\mathbf{1 . 4 8 4}$, which gives small difference between maximum and minimum thickness distribution along the cup. To examine the simulation results, experimental tests were performed one of the drawing ratios which shows the same behavior and pattern approximately.
\end{abstract}

Keywords:ANSYS9, Deep Drawing Drawing ratio.

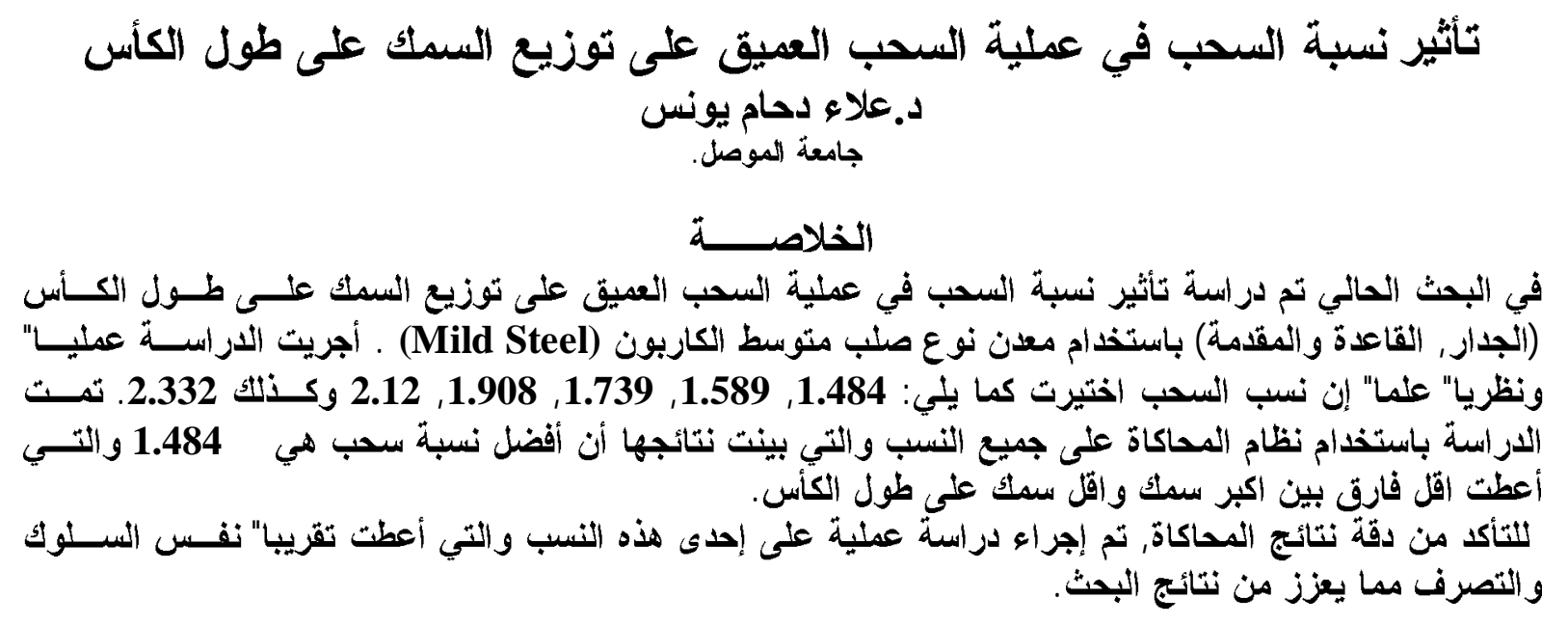




\section{NOMENCLATURE}

\begin{tabular}{|c|c|c|}
\hline $\mathrm{R}$ & Instantaneous outside radius & $\mathrm{mm}$ \\
\hline $\mathrm{r}$ & Radius of cup & $\mathrm{mm}$ \\
\hline$t_{o}$ & Original thickness & $\mathrm{mm}$ \\
\hline$\sigma_{r}$ & Radial stress & $\mathrm{MPa}$ \\
\hline$\sigma_{f}$ & Instantaneous stress & $\mathrm{MPa}$ \\
\hline$\sigma_{t}$ & Thickness stress & $\mathrm{MPa}$ \\
\hline$\sigma_{1}, \sigma_{2}, \sigma_{3}$ & Principle stresses & $\mathrm{MPa}$ \\
\hline$\sigma_{f m i}$ & Mean instantaneous stress & $\mathrm{MPa}$ \\
\hline$\sigma_{u}$ & Ultimate stress & $\mathrm{MPa}$ \\
\hline$\alpha$ & Small angle & degree \\
\hline$\beta$ & Drawing ratio & \\
\hline
\end{tabular}

\section{1-Introduction}

Deep drawing is one of the most important processes for sheet metal forming. It is the base for the mass production of part pieces for many different applications, such as lighter casings or parts of automobile bodies ....etc. Deep drawing may be defined as: it is a process in which a blank or work piece is usually controlled by pressure plate, forced into and/or through a die by means of a punch to form a hollow component in which the thickness is sub stantially the same as that of the original material [1].It is important to assess the limitations on the drawing ratio or reduction that can be accomplished successfully (i.e., without plastic instability) in a design stage so that minimum number of draws to achieve the required reduction can be used. Limiting drawing ratio (LDR) is defined as the ratio of the largest blank radius that can be successfully drawn (i.e., without failure) to the punch radius. In deep drawing process, the limiting drawing ratio depends on the characteristics of the material, die and punch design and friction condition [2].

The drawing ratio must not exceed a maximum value, in order to prevent cracks at the bottom of the cup.

When the friction between the drawn part and the punch is low, then failures will occur in the base of the part. If the friction between the part and the punch is high, the base of drawn part will be increasingly stressed with increasing friction in the can body so that the failure zone will be moved to the body of the drawn can. In order to ensure a safe production process, it is preferable to select a drawing ratio that is rather modest and less than the maximum possible value [3].

\section{2-Theoretical consideration}

The drawing ratio ( $($ ) is an important numerical value for cylindrical draw parts in determining the required number of drawing steps. The drawing ration is the ratio of the diameter of the initial blank form to the diameter of the drawn part.

Figure (1) shows a schematic view of a tool set up for a first draw.

Neglecting friction, the equilibrium condition in the radial direction in figure (1)

Can be written as [1]: 
$\left(\sigma_{r}+d \sigma_{r}\right)(r+d r) d \alpha t_{o}-\sigma_{r} r d \alpha t_{o}+2 \sigma_{t} t_{o} d r \sin \frac{d \alpha}{2}=0$

Replacing $\sin \frac{d \alpha}{2}$ By $\frac{d \alpha}{2}$ because $d \alpha$ angle is small

$\sigma_{r} r d \alpha t_{o}+\sigma_{r} d r d \alpha t_{o}+d \sigma_{r} r d \alpha t_{o}+d \sigma_{r} d r d \alpha t_{o}-\sigma_{r} r d \alpha t_{o}+2 \sigma_{t} d r \frac{d \alpha}{2} t_{o}=0$

Neglecting products of differential terms

$$
\begin{aligned}
& \sigma_{r} d r d \alpha t_{o}+d \sigma_{r} r d \alpha \quad t_{o}+\sigma_{t} d r d \alpha \quad t_{o}=0 \\
& \sigma_{r} d r+d \sigma_{r} r+\sigma_{t} d r=0 \\
& d \sigma_{r} r=-\left(\sigma_{r}+\sigma_{t}\right) d r \\
& d \sigma_{r}=-\left(\sigma_{r}+\sigma_{t}\right) \frac{d r}{r} \ldots \ldots \ldots \ldots \ldots . . .(3-2)
\end{aligned}
$$

The Tresca yield criterion $\sigma_{1}-\sigma_{3}=\sigma_{f}$

At the onset of plastic flow. Substituting $\sigma_{1}=\sigma_{r}$ And $\sigma_{3}=-\sigma_{t} \quad$ so that $\sigma_{r}+\sigma_{t}=\sigma_{f}$

The Tresca criterion predicts values which on the average are about $10 \%$. Tresca equation, a correction factor is introduced:

$\sigma_{r}+\sigma_{t}=1.1 \sigma_{f}$
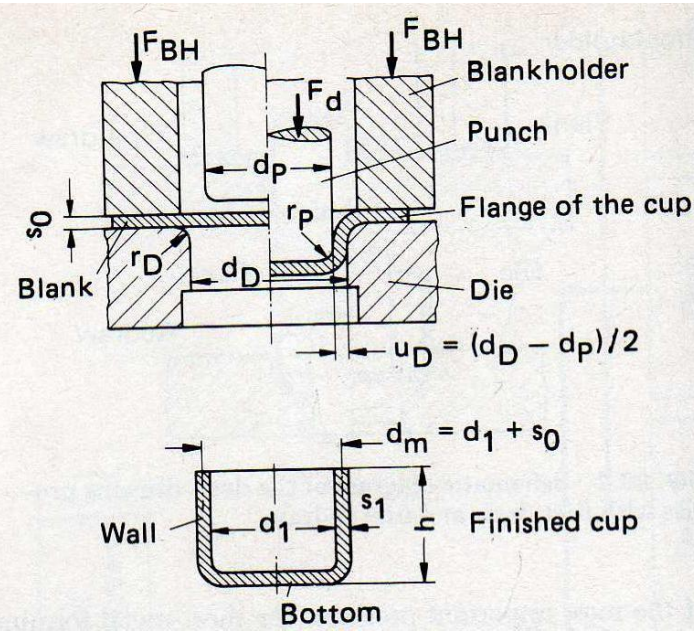

Fig. 1 Deep drawing Tool [1]

From eqns. (3-2) \& (3-4)

$d \sigma_{r}=-1.1 \sigma_{f} \frac{d r}{r}$

The radial stresses are obtained by integration of eqns. (3-5).

$\int_{0}^{\sigma_{r}} d \sigma_{r}=-1.1 \int_{R}^{r} \sigma_{f} \frac{d r}{r}$
$\sigma_{r}=1.1 \sigma_{f n i} \ln \frac{R}{r} \ldots$

Where $\mathrm{LDR}=\mathrm{R} / \mathrm{r}$

By neglecting the friction effect and blank holder force and by approximately from tensile test:

$\sigma_{\text {fmi }}=1.3 \sigma_{u}$

$\sigma_{r}=1.43 \sigma_{u} L n L D R$

$: \beta_{\max }$ To calculate the limiting drawing ratio

Ultimate tensile strength of the sheet $\sigma_{r \max }=\sigma_{u}$

$\sigma_{u}=1.43 \sigma_{u} \operatorname{LnLDR}$

Ln LDR $=0.7$

$\mathrm{LDR}=2.02$ this results as the same which calculated by Hosford [4] 


\section{3-Numerical model}

The finite element method has become a powerful tool of numerical solution wide range of engineering problems. In this method of analysis a complex region defining a continuum is discretzed into simple geometric shapes called finite elements. In the finite element method it will often be possible to improve or refine the approximate solution by spending more computational effort. The solution region is considered as built up of many small, interconnected sub regions called finite elements [5].

Three type's elements are selected:

1 -Visco106 to represent the blank.

2-TARGET169 to represent the tool.

3-CONTACT171 to represent thee contact between blank and tool.

In this work the commercial FEM code (ANSYS 9) are used to simulate the process of deep drawing operation.

Cup forming was created and the numerical results were comparing with the experimental results.

\section{4- Experimental work}

With the use of the same conditions as those set for the finite element simulations. The experiment was carried out using the INSTRON testing machine which has a capacity of machine $100 \mathrm{KN}$ the crosshead speed of the testing machine was kept constant at $10 \mathrm{~mm} / \mathrm{min}$. A typical cylindrical cup drawing process was chosen for detailed analysis in deep drawing process with draw beads. The cup $(49.9 \mathrm{~mm})$ outer diameter with corner radius $r_{d}=6 \mathrm{~mm}$. and $(22 \mathrm{~mm})$ height is axisymmetric and the blank from which it is formed has a diameter $(82 \mathrm{~mm})$, the punch $(47.1 \mathrm{~mm})$ diameter with corner radius $r_{p}=2 \mathrm{~mm}$., a thickness of $(1 \mathrm{~mm})$ mild steel. This cup without flange, and completely drawn into the die shown in figure (2).

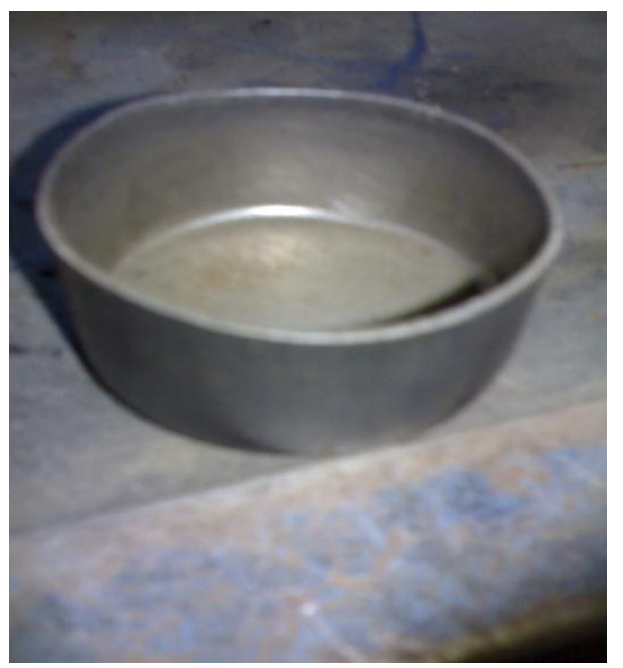

Figure (2) the sample of completely drawn cup

\section{5- Results and discussions}

In this paper the variable study the size of blank and the effect has been explained and discussed upon the deep drawing during process, using six different sizes of blank. The relations between the distance from cup center with the strain, stress and thickness were also 
discuses, also the load relation with the punch displacement was considered. Comparisons of numerical and experimental results were carried out for only one case (one size of blank).

Figure (2) shows the completely drawn cup from the experimental process, it can be seen from this figure there is no wrinkling and the difference between the maximum and minimum thickness is very small, so that good uniform distribution thickness

Along the cup has been achieved.

Figure (3) represents the relationship between draw force (punch load) and displacement in case of the theoretical and experimental results(which calculated by the INSTRON test machine directly). It can be seen that both curves have the same pattern.

Figure (4) shows the relationship between the thickness distribution and distance from the cup center, these curves are similar and has no significant change between theoretical and experimental results (which calculated by the Tip Micrometer).

Figure (5) shows the relationship between thickness and distance from the cup center for all the drawing ratios considered cases. It can be observed that the best results is founded at drawing ratio of 1.484 , which gives minimum variation between maximum and minimum thickness distribution (approximately 0.05) along the cup, so that this value is less than the LDR which calculated in the theoretical consideration.
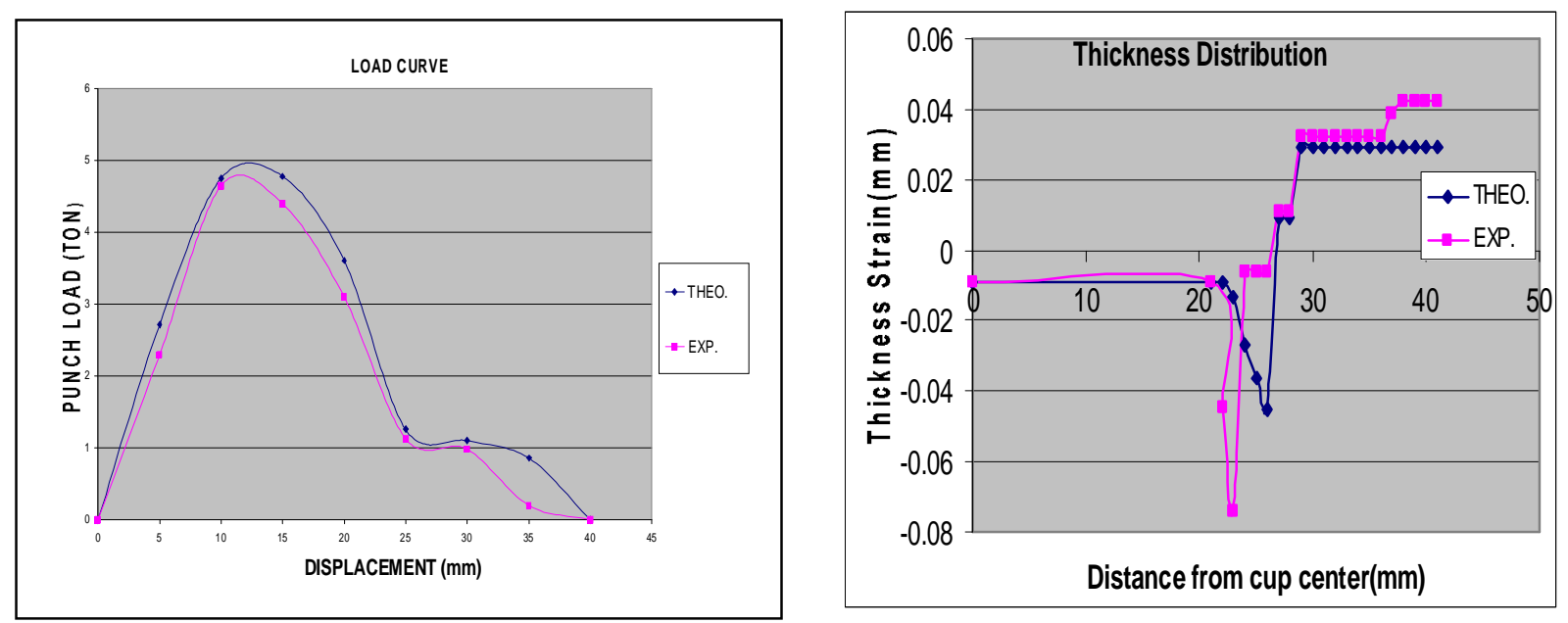

Fig. (3) Theoretical and experimental load curve

Fig. (4) Theoretical and experimental Thickness distribution

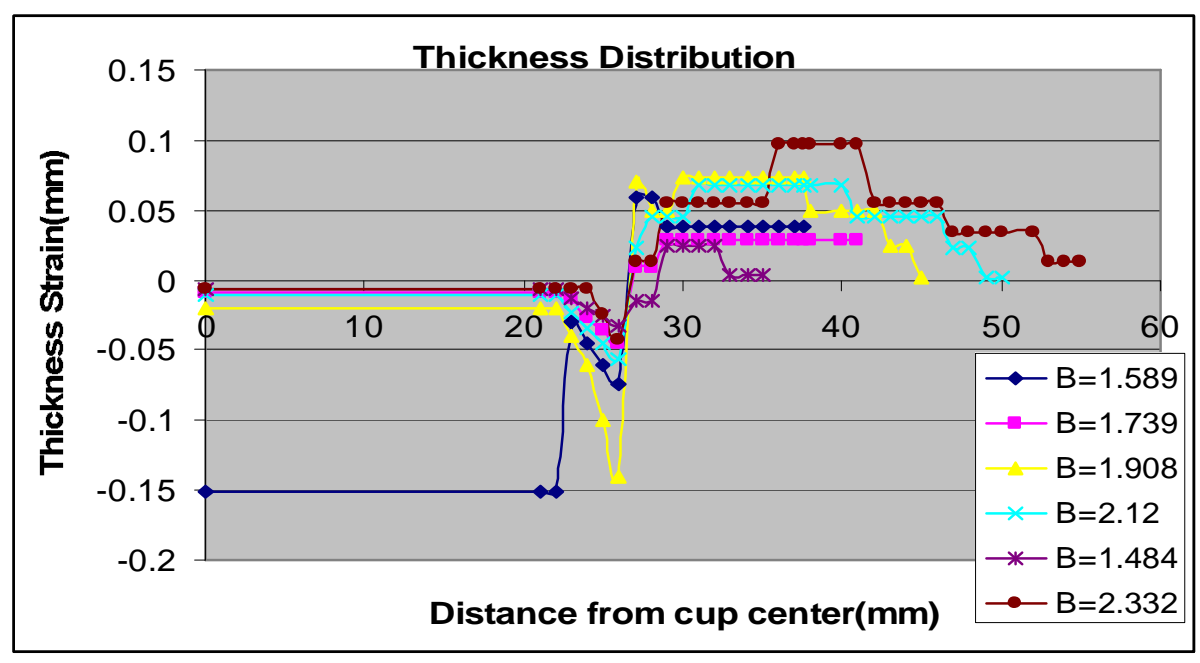




\begin{tabular}{llll} 
Al-Rafidain Engineering & Vol.18 & No.4 & August 2010 \\
\hline
\end{tabular}

Fig. (5) The effect of drawing ratio on the thickness distribution

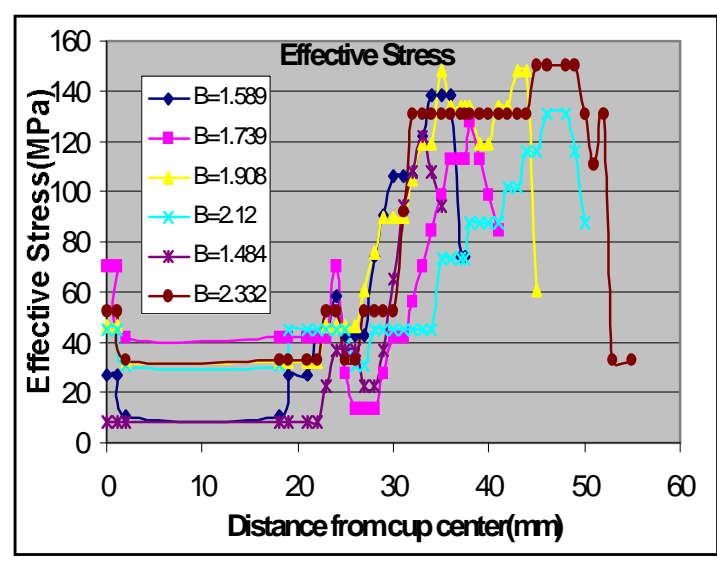

Fig. (6) The effect of drawing ratio on the effective strain

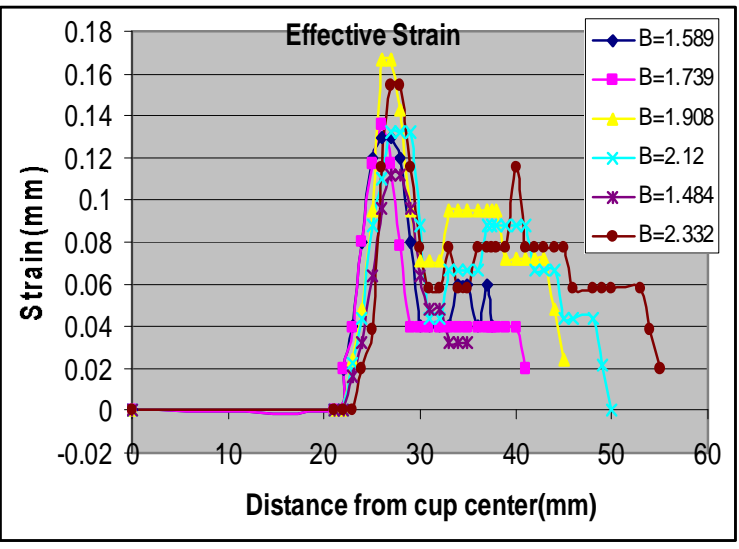

Fig. (7) The effect of drawing ratio on the effective stress

Figure (6) represents the relationship between the effective strain and distance from the cup center, which gives the maximum value at drawing ratio of 1.908 . It can be pointed out that the difference values of the effective strain is high near the center radius (under punch) because the action equal biaxial tension and will gradually decrease as move away towards the edge.

Finally, figure (7) represents the relationship between the effective stress and the distance from cup center. In all considered cases, the behavior is observed to be uniform and similar approximately. Where the effective stress show low value and almost constant under the punch base, because there is no forming would take place under the punch base. After that the effective stress increases on the cup wall until reached the maximum value at the end of the cup wall.

\section{References}

1. Kurt Lange, Hand Book of metal forming, university of Stuttgart 1985.

2. Prakash S., N. Venkata and G.K.L., on multistage deep drawing of axisymmetric components, India institute of technology, May 2003.

3. Schuler $\mathrm{GmbH}$, metal forming Hand Book, springer-veriag Berlin Heidelberg 1998.

4. William F. Hosford, mechanical behavior of materials, Cambridge University press 2005.

5. Rao, the finite element method in engineering, Robert Maxwell, San Diago state university, USA 1982.

The work was carried out at the University of Mosul 
المجلد الثامن عثر العدد الرابع اب 2010

\section{مجلة هندسة الر اقاين}

مجلة قطرية علمية محكمة

ISSN 1813-0526

\section{هيئة التحرير}

رئيس هيئة التحرير: أ. د.عبد الحكيم حامد أحمد

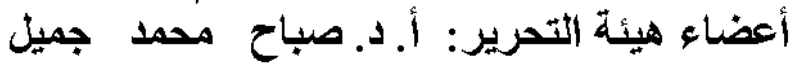

د. سامي عبد الموجود

د. دفصة رمزي العمري

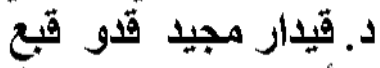

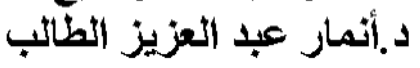

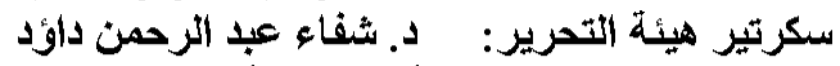

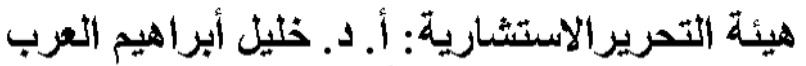

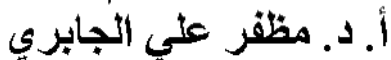

أ. أ. د. هاني محمد في فهمي

أ. أ. د. ألبير ايليا نعمان

أ. أ. د. صديق يوسف أمين ألين

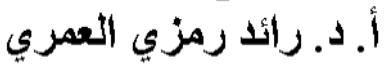

يعتبر صاحب البحث مسؤولا عن الآراء والأفكار المذكورة فيه وان أعضاء

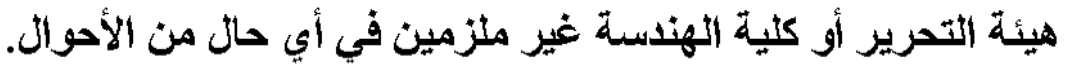

المراسلات : رئيس هيئة التحريز/ مجلة هندسة الزافين

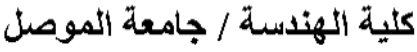

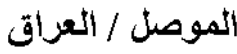

http://www.alrafidain.engineering-coll-mosul.com الموقع الالكتروني: الثبريد الاككتروني: 